\title{
Paste fill delivery/distribution failures - causes, costs and mitigation/prevention
}

\author{
A Horn URS Corp., Australia \\ EG Thomas Mine Fill Specialist Consultant, Australia
}

\begin{abstract}
Paste fill formulations focus on use of treated mine/mill waste materials and a variety of additives to reduce the impact/costs of surface waste disposal and improve pertinent underground mining parameters, in the main cost, reserves recovery and local and regional ground stability. Cost of such additives must be optimised.

Mix and/or delivery mismanagement can result in costly pipeline and/or borehole blockages. Delays to production are the main cost impacts. Actual costs of pipeline/borehole clearance are of secondary importance.

This paper first describes paste fill preparation and delivery mechanisms and then various performance failure modes including disaggregation, in-void dilution and inappropriate slurry rheology. Topics considered include fill delivery reliability, adherence to specifications, mix formulation cost effectiveness and commercially available additives.
\end{abstract}

\section{$1 \quad$ Introduction}

Design and operating characteristics at each and every mine are unique to that operation. Use of mine/mill waste placed underground via passes/pipelines/boreholes is general practice worldwide. Paste fill is transported through pipelines at any slope from horizontal to vertical and also through steeply inclined boreholes, lined or unlined. Borehole lining is usually restricted to the weathered zone overlying most orebodies, a zone usually ranging from a few metres to a few hundred metres. A wide selection of lining materials/practices is available. Unlined boreholes are prone to blockage during operation as a result of weathered material being dislodged from borehole walls. Design of fill distribution systems can be accepted as a stand-alone technology involving an understanding and control of fill rheology. Only since the wide acceptance of paste fill technology has fill rheology received serious attention and study.

Fill types are reasonably numerous and always site-specific. Only paste fill is considered in this paper. Paste fill practice is dictated in the main by the remoteness of almost all significant mines and, even more specifically, by the cost of landing a binder for the paste fill onsite reliably. Reliability of supply is critical if production schedules are to be adhered to. Such adherence differentiates between successful and not so successful mining/milling operations. Rockfills and classified mill tailing fills are not considered in this paper.

Paste fill in the main is produced from mill tailing. One potential problem in its preparation and supply is often the enthusiasm of mill managers and their over-zealousness in chasing recovery of values by grinding ore finer and finer. The mill manager's focus is recovery. The mine manager needs a suitable fill. Often a decision from above is needed to resolve this potential conflict. The best decision is one made by a general manager after advice from a competent/experienced mine fill engineer, a competent/experienced mill engineer and a cost accountant. Personalities and ambitions are often involved. In the considerable experience of one author (Thomas), once this decision is made by the general manager harmony follows and the operation prospers. The technology exists to make this process quite clear-cut once the general manager is appropriately advised. 


\section{$2 \quad$ Paste fill}

Henderson et al. (2005, p. 83) have given five criteria for paste fill:

- Contains at least $15 \%$ passing 20 microns.

- When placed, produces no supernatant or bleed water.

- Does not segregate or settle out in a pipeline.

- In rheological terms, its behaviour can be described as that of a non-Newtonian plastic or as a paste.

- Has a slump of less than $230 \mathrm{~mm}$.

Almost invariably paste fill must contain a binder to prevent its liquefaction after placement and increase its strength. The most common binder is Portland cement. Often, pozzolans such as quenched and finely ground metallurgical slags, are used as partial cement replacements to reduce costs. Paste fills are whole-tailing fills with placement densities in the range 70-80 mass percent solids, closeness to 80 mass percent solids being preferable. Tailing fines are retained to reduce coarseness/harshness to ensure positive-displacement pumpability at such high pulp densities. These fines also occupy voids that would otherwise be occupied by expensive Portland cement, as described by Thomas et al. (1979). Paste fill is essentially a no drainage fill so transport water does not need to be pumped back to the surface and minimal water is used for transport, an advantage in arid areas.

Paste fill can be regarded as a concrete with no aggregate. In concrete, Portland cement is a mixture of metal oxides (typically of calcium, aluminium and iron) which changes when hydrated to produce a liquid gel which coats each particle of sand and rock. Each cement particle forms a node that expands and coalesces with other nodes to form an initial gel structure and finally a solid mass. Whether this gel assists in fill transportation by pipeline/borehole by viscosity reduction is questionable because of the short duration of transportation from surface to underground.

Other mine fill materials (deslimed mill tailings, sand/rockfill, etc) and practice are not considered.

Brown and Ahmed (2011) begin with the statement "In the current market, operating expenditures may be preferred over capital investment". It can be argued that this statement is much more applicable today than was the case in 2011. Paste fill cost is characterised as low operating/high capital and cemented deslimed mill tailing hydraulic fill cost as high operating/low capital. Scope for choice exists.

Another significant factor worthy of consideration here is the perceived acceptance of the inherent safety of paste fill as a non-flowable material after placement and curing of its Portland cement content. Even a cursory glance through the extensive literature available indicates that this is not necessarily the case. It can be argued that cemented deslimed mill tailing hydraulic fill can be equally safe, with correct bulkhead/barricade design and construction, at much reduced capital cost and marginally higher operating cost in many cases. A case can be made that inherently safe bulkhead/barricade design and construction are attainable, for both paste fill and deslimed mill tailing fill. It could be suggested that the Standards Association of Australia and associated organisations worldwide should be approached to develop international standards for mine fill bulkhead/barricade design and construction.

\subsection{Paste fill flowability}

In its preparation, paste fill flowability (viscosity) must be engineered to ensure smooth, uninterrupted exit from the borehole/pipeline system through which it passes en route to the stope to be filled. One essential is that the distribution system remains full, without free-fall which allows segregation of coarse particles which may settle and cause a blockage. Blockages, especially where Portland cement additions are involved, which is always the case with paste fills, must be cleared and flow resumed quickly. Delays allow Portland cement hydration within the distribution system and this results in costly delays in stope filling and then production, waste of Portland cement, and costly clearing of the borehole/pipeline distribution 
system. Delays to production are the most significant. A variety of further delays/cost increases can be postulated.

\subsection{Paste fill preparation}

Stage 1 involves conventional thickening using addition of chemical coagulants to produce a thickener underflow density of close to 30 mass percent solids and clear thickener overflow water. The underflow passes to a paste thickener (Figure 1) where flocculants are added to produce an underflow in the 70-80 mass percent solids range. The third and final stage involves binder additions in a mixing tank before passage to underground.

Laboratory settling tests allow optimisation of the operation of the thickener/mixer/transport plant. Correct coagulant/flocculant selection/dosage rate are essential. Variation of ore type must be accounted for.

Coagulant and flocculant costs typically vary with ore type. Fine tailing products require additives in the AUD 2-4/t of tailing treated, typically split AUD 0.50-1/t for the coagulant step and AUD 1-2/t for the final flocculant addition. Portland cement reductions possible by replacing a conventional cemented deslimed mill tailing fill with paste fill are typically $80 \%$. The more remote the mine, the more significant is this reduction.

Operation of the paste fill plant requires co-ordination of exploration and grade control geology, stope scheduling (production and filling), concentrator/mill operation as well as ultimate mine closure and the surface impact involved. These four basic activity areas may need further sub-division to account for particular variables and controllables. Bulking out of expensive paste fill will be less expensive (all costs/cost savings considered). Rock/aggregate fill must always receive assessment. Instances of mine closure savings of AUD 5-30 million are to be expected.

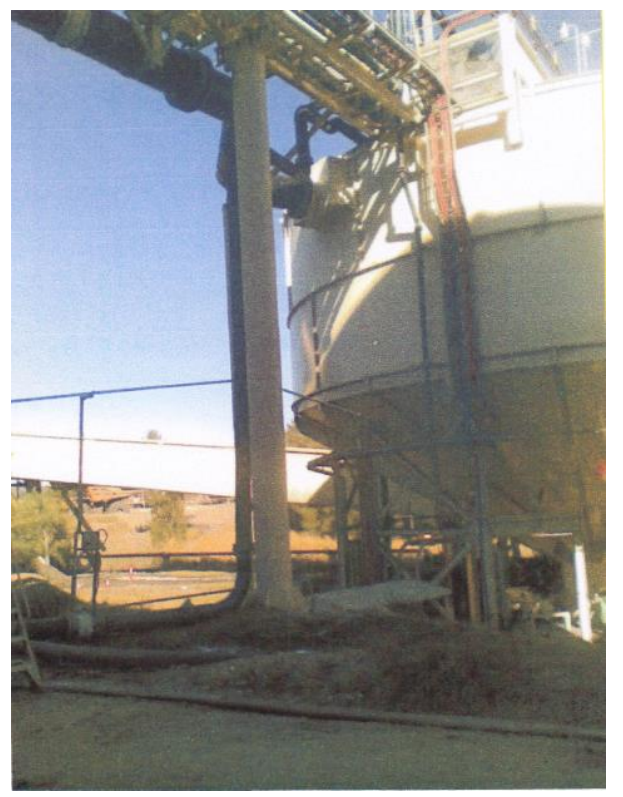

Figure 1 Typical paste thickener with truck fill conveyor in background (courtesy Outotech Pty Ltd) 


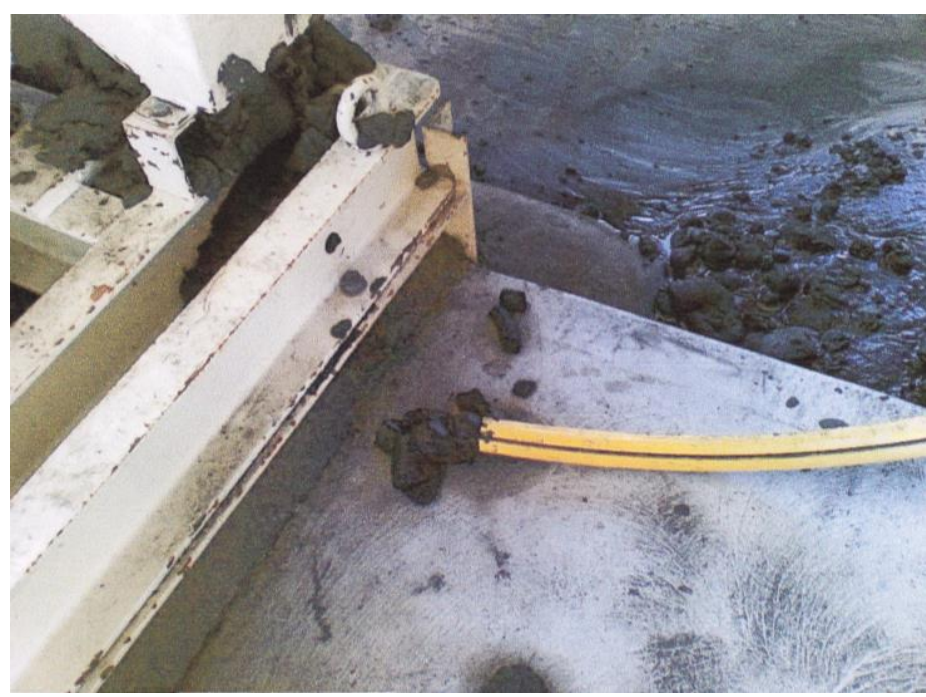

Figure 2 Thickened paste at 60 mass percent solids (courtesy Outotech Pty Ltd)

\section{Distribution failures in the published literature}

The major cause of distribution pipeline blockage is settlement of solids within horizontal sections of the fill distribution pipeline system, followed by setting of the Portland cement. Cooke (2007) shows a photo of cemented paste fill deposited under laminar flow conditions in a horizontal pipe, with extensive and comprehensive discussion of paste fill flow characteristics. Left unattended and unrectified, a costly line blockage and its downstream effects are indicated. Goosen et al. (2011) report on a novel online detection method which is described in detail, with supporting discussion of paste fill flow characteristics. This consists of an all metal, nonintrusive pipe spool.

A further common cause of blockages in distribution lines is foreign objects, oversize solid objects that should not be present in the fill line. Three examples are:

- Handheld tools, such as hammers, left by maintenance staff after shutdowns. Each mixing and holding/distribution tank requires a grill at its exit point.

- Cemented scale from the upper walls of mixing tanks and structures above mixing tanks if the tanks are not covered.

- Rock fragments from the walls of unlined boreholes.

This list is far from comprehensive.

\section{$4 \quad$ Logistics}

Most mines are remote and everything required for their operation needs to be transported to site. In the case of paste fill, equipment (pumps, pipeline, fittings and instrumentation) needs meticulous warehousing and Portland cement and any additives need onsite storage. Each operation has its unique characteristics. The basic principle to be adopted is that any delay in filling will impact on the mine production schedule. This impact is usually much greater than increased labour costs incurred in distribution system blockages. Taking just one example, the situation has occurred where a mine remote from its cement supplier, with cement transport by rail through flood-prone terrain, was delayed in a critical pour of cemented fill for some weeks. The saving grace in this particular case was the availability of multiple stopes which allowed production to continue. However, an important lesson was learned by all concerned. 


\section{$5 \quad$ Impacts of salinity and fill/country water quality}

The correct hydration of Portland cement requires appropriate water quality. This applies to both concrete and cemented mine fill. With cemented mine fill quality of both mix and country water must be appropriate. Considering just one example, magnesium sulphate is known to react with the free calcium hydroxide in fill cement, resulting in cement strength breakdown by formation of calcium sulphate and magnesium hydroxide (Lea 2004).

Pretorius et al. (2011) report comprehensively on salinity effects in brine based fly ash pastes.

Any potential threat from either/both mix water/ground water must be assessed and appropriate countermeasures developed and applied.

\section{Conclusions}

Quality control procedures for paste fill are stringent.

Paste fill preparation requires close liaison among many planning and operating geology, mining, milling, and costing departments.

The consequences of blockages and related problems must be closely considered from conception, throughout operation and into mine closure.

\section{Acknowledgement}

Outotech Pty Ltd has supplied paste fill plant photographs for this paper and this is acknowledged with appreciation.

Belinda Thomas has been most helpful in the computing aspects of the preparation of this paper.

\section{References}

BASF Australia Ltd 2012, BASF Minefill Products Brochure, BASF Australia Ltd, Southbank.

Brown, R \& Ahmed, I 2011, 'Backfilling on a budget: low capital paste backfill injection for small mines or brownfield site remediation', Proceedings of the 10th International Symposium on Mining with Backfill, ed. HG Ilgner, The Southern African Institute of Mining and Metallurgy, Johannesburg, pp. 35-40.

Cooke, R 2007, 'Backfill pipeline distribution systems - design methodology review', in F Hassani \& J Archibald (eds), Proceedings of the 9th International Symposium on Mining with Backfill, Canadian Institute of Mining, Metallurgy and Petroleum, Westmount.

Goosen, P, Ilgner, H \& Dumbu, S 2011, 'Settlement in backfill pipelines: its causes and a novel online detection method', in HG Ilgner (ed.), Proceedings of the 10th International Symposium on Mining with Backfill, The Southern African Institute of Mining and Metallurgy, Johannesburg, pp. 187-96.

Henderson, A, Revell, MB, Landriault, D \& Coxon, J 2005, 'Paste Fill', in Y Potvin, EG Thomas \& AB Fourie (eds), Handbook on Mine Fill, Australian Centre for Geomechanics, Perth, Western Australia.

Lea, FM 2004, 'Chemical Action', in PC Hewlett (ed.), Lea's Chemistry of Cement and Concrete, 4th edn, Elsevier Ltd, Kidlington, Oxford.

Pretorius, PC, Mahlaba, JS, Nzotta, U \& Hareeparsad, S 2011, 'Fundamental research on brine-based fly ash pastes for underground disposal', in HG Ilgner (ed.), Proceedings of the 10th International Symposium on Mining with Backfill, The Southern African Institute of Mining and Metallurgy, Johannesburg, pp. 21-8.

Thomas, EG, Nantel, JH \& Notley, KR 1979, Fill Technology in Underground Metalliferous Mines, International Academic Services Limited, Kingston, Ontario. 
